\title{
STUDY ON THE POZZOLANIC ACTIVITY OF SUGAR CANE STRAW ASH PRODUCED USING DIFFERENT PRETREATMENTS
}

\author{
Guilherme Chagas Cordeiro*, Amanda Pereira Vieira and Érica da Silva Lopes \\ Laboratório de Engenharia Civil, Universidade Estadual do Norte Fluminense Darcy Ribeiro, 28013-602 Campos dos Goytacazes \\ - RJ, Brasil
}

Recebido em 18/07/2016; aceito em 07/12/2016; publicado na web em 05/02/2017

\begin{abstract}
This work systematically describes a laboratory study on different pretreatments of sugar cane straw to produce pozzolanic ash. Two procedures were used to accelerate the hydrolysis of celluloses and hemicelluloses and remove metallic impurities present in significant levels in sugar cane straw: hot water washing and acid leaching. Proximate analysis by thermogravimetry was carried out to cover volatile matter, fixed carbon, and ash content of the different straws. Detailed measurements of X-ray diffraction, oxide percentages, loss on ignition, and BET specific surface area were performed to compare hot water washed, acid leached, and nonpretreated ashes, after controlled processes of burning and grinding. The pozzolanic activity of the ashes was evaluated from the modified Chapelle and electrical conductivity methods. The results revealed that ashes with a high content of amorphous silica were produced, in spite of the straw pretreatments. However, both straw pretreatments induced a significant increase in pozzolanic activity, mainly associated with the removal of impurities, especially $\mathrm{CaO}, \mathrm{SO}_{3}, \mathrm{~K}_{2} \mathrm{O}$, and carbon compounds. The effect of the hot water washing treatment was relatively small in relation to the acid leaching, but the hot washed ash was significantly more pozzolanic than non-treated ash.
\end{abstract}

Keywords: sugar cane straw ash; pozzolan; pozzolanic activity; leaching acid pretreatment.

\section{INTRODUCTION}

Sugar cane is an important agricultural crop cultivated in tropical countries, with an annual world production of approximately 1.9 billion tonnes. ${ }^{1}$ Sugar cane field burning has been widely practiced in many parts of the world during sugar cane harvest. Although the burning process facilitates and speeds up harvest operations in comparison with the cutting of unburned cane, it is also a source of many environmental problems, such as the increase in the atmospheric pollution levels, the reduced range of view near highways and airports due to the smoke curtain formed, and even the burning of residences. For this reason, strongly restrictive laws have been passed in different countries to reduce or eliminate field burning, such as in Brazil for example, which is the world's main sugar cane producer. With approximately 350 million tonnes (51 wt.\%) harvested in $2014,{ }^{2}$ the State of São Paulo is the main producer of sugar cane in Brazil and its State Legislative has passed an agro-environmental protocol requiring the total termination of field burning by $2017 .{ }^{3}$ Thus, a great deal of attention has been devoted to mechanized harvest methods, which do not involve sugar cane burning.

The prohibition of burning may considerably increase the production of steam and electricity from sugar cane biomass because harvest burning removes about $80 \%$ of the trash mass, including tops and green and dry leaves. ${ }^{4}$ Moreover, the harvest of green cane avoids the death of the native soil microbiota, and helps to replenish nutrients when part of the straw has been left in the field. ${ }^{5}$ It is important to note that about $50-90 \%$ of straw could be removed from harvest sites as a means to avoid accidental burning, which eventually would slow down the growth of new sugar cane shoots. Therefore, approximately 90 million tonnes of straw on a dry basis may potentially be produced annually by the sugar cane industry in Brazil. This stands as a considerable advantage since the energetic potential of this biomass is about $30,000 \mathrm{GW}$, considering that the straw calorific value is $15 \mathrm{~kJ} \mathrm{~kg}^{-1}$ and the conversion efficiency is $30 \%{ }^{6}$

\footnotetext{
*e-mail: gcc@uenf.br
}

Sugar cane bagasse ash (SCBA) has been used as a supplementary cementitious material (or simply referred to as pozzolan) for Portland cement in concrete..$^{7-10}$ The pozzolanic activity of a material is related to its potential to generate amorphous siliceous/aluminous compounds that will chemically react with calcium hydroxide in the presence of water at ambient temperature to produce calcium silicate hydrate. It is well known that SCBA presents pozzolanic activity due to its high silica content and the presence of partially amorphous silica, associated with its high specific surface area. ${ }^{11}$ Recent studies have suggested the viability of sugar cane straw ash (SCSA) for the same applications as those of SCBA. ${ }^{12-15}$ For example, Martirena et al. ${ }^{12}$ studied the pozzolanic activity of a SCSA by X-ray diffraction and thermogravimetric analyses. They reported that the SCSA was comparable to rice husk ash (RHA), which is the most important agricultural-sourced pozzolan. The use of SCSA as pozzolan presents itself as a very interesting environmental alternative for waste reuse, especially in light of the changes that the sugar cane industry has faced in recent years.

Previous studies have shown that the pozzolanic potential of SCBA may be improved by controlled calcination ${ }^{11,14,16}$ and mechanical grinding ${ }^{9,17,18}$ processes. Moreover, different studies have shown that the pozzolanic properties of RHA may be strongly enhanced through prior acid leaching of husk. In this case, it is possible to produce a high-purity amorphous silica with high specific surface area by removing carbon and other metallic impurities before calcination. ${ }^{19,20}$ It has been found that potassium oxide from rice husk causes the negative effect of the silica surface melting and the crystallization of amorphous silica into cristobalite and tridymite..$^{21,22}$

Considering that there are few studies on the properties of SCSA and that works investigating the influence of pretreatment of sugar cane bagasse and straw ashes on the pozzolanic activity are rare, this research aims at studying the feasibility of producing pozzolanic materials from sugar cane straw submitted to different pretreatments. Detailed measurements of X-ray diffraction, oxide percentages, loss on ignition, and BET specific surface area were performed to compare 
three different ashes: non-pretreated SCSA, hot water-washed SCSA, and acid-leached SCSA. The pozzolanic activity of these ashes was evaluated using the modified Chapelle and electrical conductivity methods.

\section{EXPERIMENTAL}

\section{Pretreatment of straw samples and production of ashes}

Sugar cane straw (SCS) was obtained from an experimental farm of the Rural Federal University of Rio de Janeiro located in the city of Campos dos Goytacazes (State of Rio de Janeiro, Brazil). In laboratory, SCS samples were cut to $20 \mathrm{~cm}$ pieces by scissors, washed with distilled water, and oven-dried at $80{ }^{\circ} \mathrm{C}$ for $24 \mathrm{~h}$. After that, the dried SCS was milled using a 20-mesh sieve on a laboratory Willy mill (Thomas) and separated to produce three different straw ashes.

Two SCS pretreatments were used in this research. The first one was conducted with hot deionized water washing. In this case, a 40-g SCS sample was washed with $1 \mathrm{~L}$ of boiled water for $2 \mathrm{~h}$, filtered through 41 Whitman filter paper, and oven-dried at $80{ }^{\circ} \mathrm{C}$ for 24 $\mathrm{h}$. The second pretreatment was an acid leaching based on a study on the pozzolanic properties of RHA by hydrochloric acid $(\mathrm{HCl})$ pretreatments. ${ }^{20}$ Thus, $40 \mathrm{~g}$ of dried SCS were firstly maintained in 1 L of $1 \mathrm{~mol} \mathrm{~L}^{-1} \mathrm{HCl}$ (analytical grade, Sigma-Aldrich) aqueous solution at $90{ }^{\circ} \mathrm{C}$ for $2 \mathrm{~h}$. After that, the solution with SCS was filtered and rinsed eight times with distilled water. This repetition was found to be necessary in order to remove the remaining acidic impurity. Then, the SCS was oven-dried at $80^{\circ} \mathrm{C}$ for $24 \mathrm{~h}$. Three straw samples were denominated IN-SCS, WW-SCS, and HL-SCS to designate in natura, water-washed, and $\mathrm{HCl}$-leached SCS samples, respectively.

Proximate analyses of SCS samples were performed by thermogravimetric analysis (TGA) conducted in a Hitachi 7300 analyser according to Cordeiro and Sales. ${ }^{23}$ In each test, approximately $15 \mathrm{mg}$ of sample was used with a platinum crucible in a two-gas stage experiment. The SCS samples were gradually heated from ambient temperature to $105{ }^{\circ} \mathrm{C}$ under a $\mathrm{N}_{2}$ flow $\left(75 \mathrm{~cm}^{3} \mathrm{~min}^{-1}\right)$ at $20{ }^{\circ} \mathrm{C} \mathrm{min}^{-1}$ heating rate, and $5 \mathrm{~min}$ hold up time, and then at $25^{\circ} \mathrm{C}$ $\mathrm{min}^{-1}$ heating rate to $950^{\circ} \mathrm{C}$ with a hold time of $18 \mathrm{~min}$, being the last 6 min under oxidizing conditions $\left(75 \mathrm{~cm}^{3} \mathrm{~min}^{-1}\right.$ synthetic air flow). Thus, firstly the moisture content and volatile matter were determined at $\mathrm{N}_{2}$ atmosphere. After a 12-min equilibration time at $950{ }^{\circ} \mathrm{C}$, the atmosphere was switched to synthetic air; then, the sample began to degrade under combustion, and the ash content was properly quantified. The percent values of moisture $(M)$, volatile matter $(V)$, and ash (A) were calculated by Equations (1), (2), and (3), respectively. In addition, fixed carbon $(C)$ was obtained by difference (Equation 4). Median values were calculated from three replications.

$$
\begin{gathered}
M=\frac{W-W_{M}}{W} 100 \\
V=\frac{W_{M}-W_{V}}{W} 100 \\
A=\frac{W_{A}}{W} 100 \\
C=100-(M+V+A)
\end{gathered}
$$

Considering $W$ the original sample mass, $W_{M}$ the sample mass after drying at $105{ }^{\circ} \mathrm{C}, W_{V}$ the sample mass after the complete volatilization (at about $32 \mathrm{~min}$ ), and $W_{A}$ the sample mass after heating at $950{ }^{\circ} \mathrm{C}$ under an oxidizing atmosphere (at about $59 \mathrm{~min}$ ). $W_{V}$ and
$W_{A}$ mass values were taken from TGA curves considering the peaks on derivative thermogravimetric analysis (DTG) curves.

Three ashes were produced by burning of the in natura and pretreated SCSs after an oven-drying at $80^{\circ} \mathrm{C}$ for $24 \mathrm{~h}$. The burning was performed in a muffle furnace at $10{ }^{\circ} \mathrm{C} \mathrm{min}{ }^{-1}$ heating rate in two steps: at $350{ }^{\circ} \mathrm{C}$ for $3 \mathrm{~h}$, and at $700{ }^{\circ} \mathrm{C}$ for another $3 \mathrm{~h}$. The sample was left to cool down inside the furnace. This burning approach was established in function of the TGA of SCS samples. A similar burning procedure was previously used to produce ashes containing high amorphous silica and low loss on ignition from sugar cane bagasse $\mathrm{e}^{11,16}$ and elephant grass. ${ }^{23}$ The ashes produced from burning of IN-SCS, WW-SCS, and HL-SCS were denominated IN-SCSA, WW-SCSA, and HL-SCSA, respectively. After burning, the three SCSAs were dry ground for $15 \mathrm{~min}$ in a rotation speed of $150 \mathrm{rpm}$ in a Fritsch Pulverisette 5 planetary mill. Each grinding was performed with a $40-\mathrm{g}$ ash sample in a $500-\mathrm{cm}^{3}$ jar with 83 alumina balls (diameter of $10 \mathrm{~mm}$ ). The grinding approach was defined to produce ashes with particle size $D_{50}(50 \%$ passing size $)$ about $10 \mu \mathrm{m} .{ }^{24}$

\section{Characterization of SCSAs}

Particle size distributions of ground ashes were measured using a Malvern Mastersizer 2000 laser diffraction particle analyzer operating in liquid mode with deionized water as dispersant, and ultrasonic agitation for $60 \mathrm{~s}$. Oxide concentrations were measured by X-ray fluorescence spectrometry (XRF) using a Phillips PW2400 spectrometer, and the values of loss on ignition were obtained according to the ASTM C114$15 .^{25}$ The BET specific surface area $\left(\mathrm{N}_{2}\right.$ adsorption) was determined using a Micromeritics ASAP 2020 physisorption analyser. The density was determined using a Micromeritics Accupic helium pycnometer. Also, the morphology of SCSA particles was assessed by scanning electron microscope (Jeol JXA840-A) images. The samples were carbon-coated under vacuum. X-ray diffraction data were collected using a $\mathrm{Cu}-\mathrm{K} \alpha_{1}$ radiation Bruker D8 Focus diffractometer operating at $40 \mathrm{~mA}$ and $40 \mathrm{kV}$. Scans were over a $2 \theta$ angle range from 8 to $60^{\circ}$, at an angular step of $0.02^{\circ}$, and a counting time of $1.0 \mathrm{~s}$. The XRD data were identified using the DiffracPlus EVA software (Bruker) according to the ICDD pdf-2 database.

The pozzolanic activity of SCSAs was evaluated using two different methods. The first was the electrical conductivity method proposed by Lúxan et al. ${ }^{26}$ where the variation of the electrical conductivity of a saturated solution of calcium hydroxide $(96 \%$ purity, Vetec) with $1.75 \mathrm{~g}$ of the sample, with constant agitation at $40 \pm 1{ }^{\circ} \mathrm{C}$, was continuously monitored over $20 \mathrm{~min}$ using a portable conductivity meter (Alfakit 230). The conductivity test was conducted three times for each ash. Lúxan et al. ${ }^{26}$ proposed a classification criterion of material with respect to its pozzolanic property based on the variation of conductivity $(\Delta C) 2$ min into the test (Table 1$)$. In this case, the greater the change in the conductivity of solution added with the sample, the more pozzolanic the sample was.

Table 1. Classification of pozzolanicity proposed by Luxán et al. ${ }^{26}$

\begin{tabular}{lc}
\hline Classification of the material & $\Delta \mathrm{C}\left(\mathrm{mS} \mathrm{cm}^{-1}\right)-2 \mathrm{~min}$ \\
\hline Non-pozzolanic & Less than 0.4 \\
Variable pozzolanicity & Between 0.4 and 1.2 \\
Good pozzolanicity & Greater than 1.2 \\
\hline
\end{tabular}

The second pozzolanic method consisted of the modified Chapelle test based on Raverdy et al., ${ }^{27}$ at which the pozzolanic activity was determined by the calcium hydroxide content fixed by pozzolan. The tests consisted of placing $2.0000 \mathrm{~g}$ of $\mathrm{CaO}$ (99.9\% purity, Vetec), 
$1.0000 \mathrm{~g}$ of the material to be evaluated and $250.0 \mathrm{~mL}$ of $\mathrm{CO}_{2}$-free water in a flask and kept in a Dubnoff shaking water bath (type 304E, Nova Ética) for $16 \mathrm{~h}$ at $90 \pm 5^{\circ} \mathrm{C}$. After cooling, $250 \mathrm{~mL}$ of a saccharose solution $\left(240 \mathrm{~g} \mathrm{~L}^{-1}\right)$ was added and shaken for $15 \mathrm{~min}$ in order to dissolve the free $\mathrm{Ca}(\mathrm{OH})_{2}$. Then, the solution was filtered through a pleated filter paper with an aliquot of $50 \mathrm{~mL}$, the alkalinity was determined with hydrochloric acid $0.1 \mathrm{~mol} \mathrm{~L}^{-1}$ titration. The value of the pozzolanic activity was expressed by the quantity in milligrams of $\mathrm{CaO}$ reacted or fixed per gram of pozzolan.

\section{RESULTS AND DISCUSSION}

\section{Proximate analysis of straw samples}

The mass loss (TGA) and derivative (DTG) curves of the straw samples are represented as a function of time in Figures 1a and $1 \mathrm{~b}$, respectively. The temperature profile used in these analyses is also indicated in Figure 1. The results of mass loss in each specific temperature range are indicated in Table 2. All samples exhibited the same behavior under heating, with three well-defined stages. A small initial mass loss peak could be observed between $25{ }^{\circ} \mathrm{C}$ ambient temperature and $105^{\circ} \mathrm{C}$. This mass loss was associated with evaporable moisture. The second and main DTG peak, which was observed between 200 and $500{ }^{\circ} \mathrm{C}$, was indicative of the devolatilization of lignocellulosic compounds. In this case, the maximum rate of mass loss occurred around $350^{\circ} \mathrm{C}$. It should be recalled that this temperature was selected in the first step of the SCS burning process. The last peak, observed at $950{ }^{\circ} \mathrm{C}$ after the atmosphere change from $\mathrm{N}_{2}$ to synthetic air, was related to the complete combustion of samples.
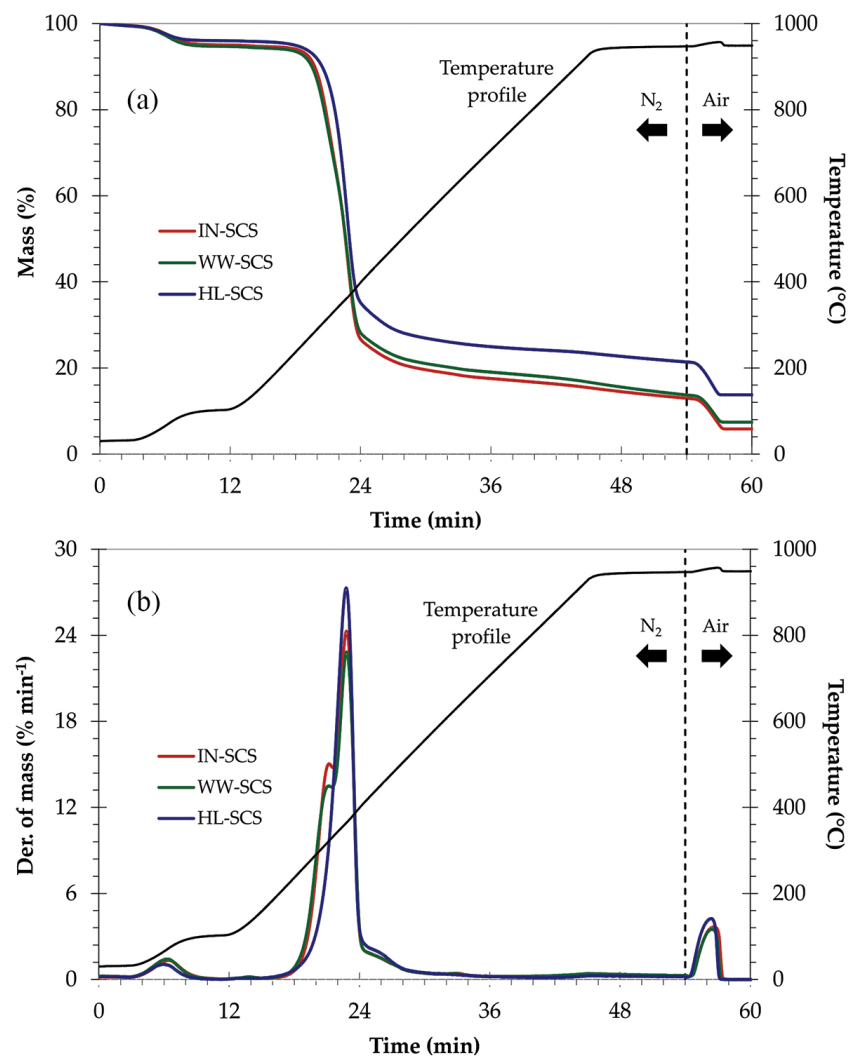

Figure 1. TGA (a) and DTG (b) curves of SCS samples

Figure 2 shows the quantification of volatile matter, fixed carbon, and ash content in dry basis for all SCS samples from values showed in Table 2. A considerable increase in the ash content was observed
Table 2. Values of mass loss (\%) of sugar cane straw (SCS) samples

\begin{tabular}{lccc}
\hline Sample & $W_{M}$ & $W_{V}$ & $W_{A}$ \\
\hline IN-SCS & 5.30 & 82.37 & 94.18 \\
WW-SCS & 5.75 & 81.32 & 92.60 \\
HL-SCS & 4.34 & 75.74 & 86.29 \\
\hline
\end{tabular}

for the pretreated samples, indicating the positive effect of both pretreatments prior to burning. This was due to the removal of organic compounds by leaching, thus increasing the ash concentration. The highest ash content (14.3\%) was verified in the HL-SCS, and it was approximately $130 \%$ higher than that observed for IN-SCS. The WW-SCS had an intermediate ash content (7.9\%), about $30 \%$ higher than IN-SCS.

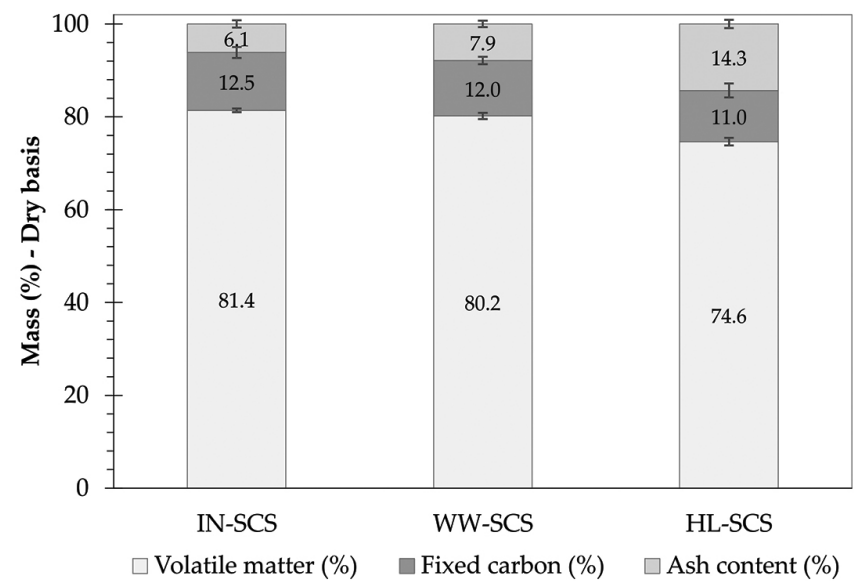

Figure 2. Proximate analysis results of SCS samples determined from TGA/ DTA analyses

\section{Particle size distribution, BET specific surface area, and SEM images of ashes}

It can be seen from Figure 3 the particle size distribution of the different ashes. The characteristic particle size $D_{50}(50 \%$ passing size) values were approximately $10 \mu \mathrm{m}$, as indicated in Table 3 . Grinding procedures were effective to equalize all particle size distributions since there were no expressive differences in relation to the $D_{50}$ values. The same was observed by comparing the complete particle distribution curves. It should be emphasized that the particle size

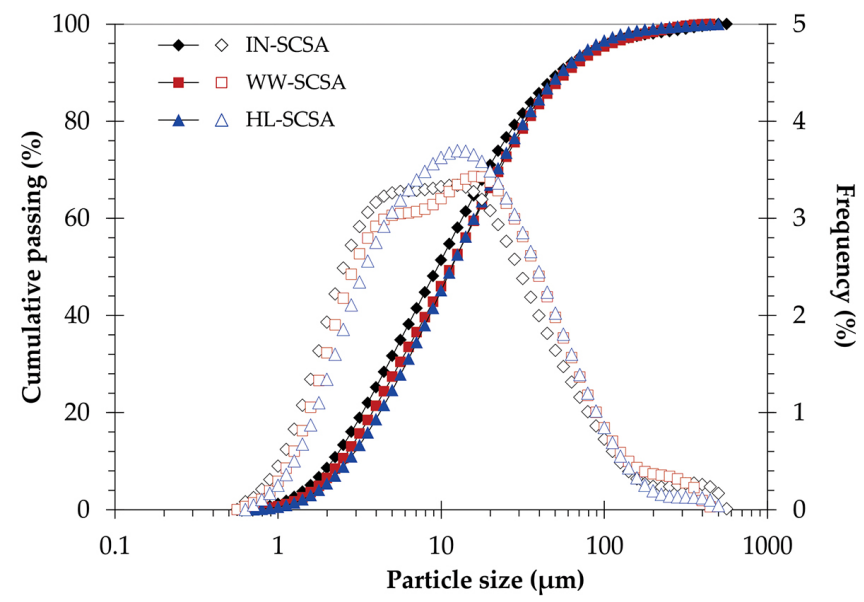

Figure 3. Cumulative (full symbols) and frequency (hollow symbols) particle size distribution curves of SCSA samples 
Table 3. Values of $D_{50}$ and BET specific surface of SCSA samples

\begin{tabular}{lccc}
\hline Characteristic & IN-SCSA & WW-SCSA & HL-SCSA \\
\hline$D_{50}(\mu \mathrm{m})$ & 9.52 & 11.51 & 11.64 \\
BET specific surface area $\left(\mathrm{m}^{2} \mathrm{~g}^{-1}\right)$ & 47.96 & 71.16 & 433.78 \\
\hline
\end{tabular}

distributions of the SCSAs had to be similar for the purposes of the present study since the pozzolanic activity was recognized as strongly dependent on the particle size. ${ }^{28}$

Although the high energy grinding had afforded to produce ashes with similar particle size distributions, HL-SCSA presented an extremely high specific surface area (by $\mathrm{N}_{2}$-adsorption), nearly 10 times as high as that for IN-SCSA (Table 2). As reported by some previous studies about RHA, acid pretreatment prior to calcination was appropriate to obtain high specific surface ashes. ${ }^{20,22}$ This behavior was largely due to the removal of metallic oxides, mainly $\mathrm{K}_{2} \mathrm{O}$, which enabled a better removal of volatiles and organic materials during the calcination process. ${ }^{22}$ In fact, the specific surface area was greatly affected by the acid leaching of straw. This was in agreement with the results of the proximate analysis (Figure 2). The typical scanning electron microscopy image, shown in Figure 4, indicated that the HLSCSA had very porous structure, confirming its high specific surface value. Table 3 also shows the specific surface of the WW-SCSA, which was about 1.5 times that of the IN-SCSA, indicating improvement in calcination after the hot washing of SCS due to a better removal of volatile matter and fixed carbon in comparison with the nonpretreated ash.
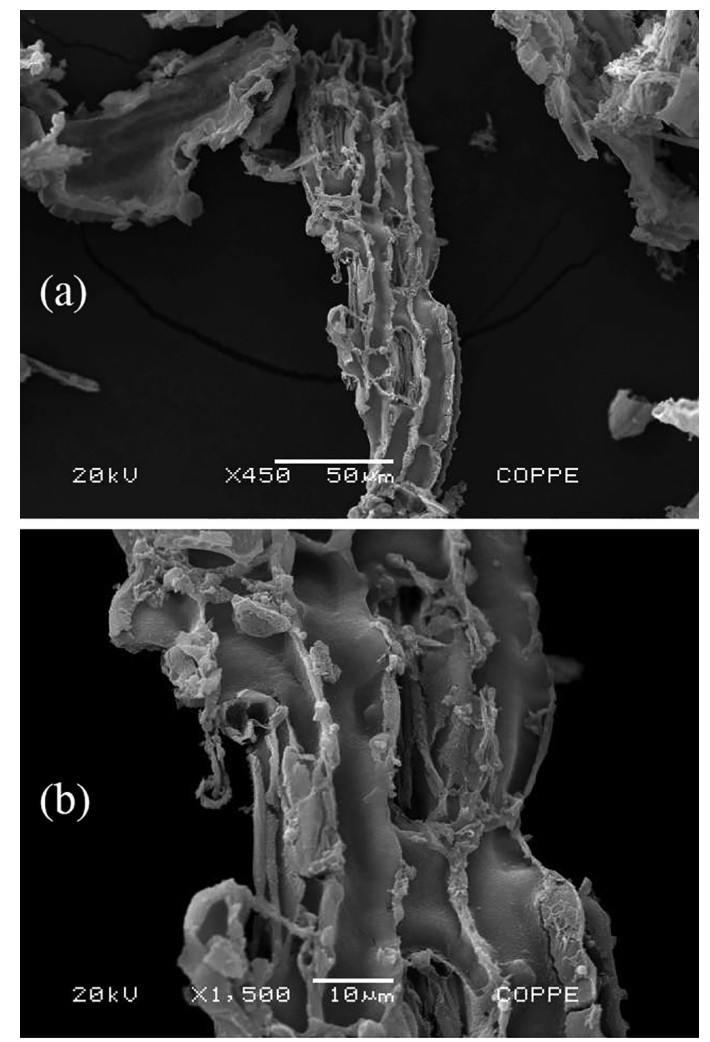

Figure 4. Scanning electron micrographs of a HL-SCSA particle with $\times 450$ (a) and $x 1500$ (b) of magnification

\section{Oxide percentages, loss on ignition, and X-ray diffraction of} ashes

The results of oxide concentrations of SCSA samples are presented in Table 4. As expected, silica was the major oxide constituent in the IN-SCSA, which is very important to use as pozzolan since in amorphous or partially crystalline state. Some minor quantities of $\mathrm{CaO}, \mathrm{SO}_{3}$, and $\mathrm{K}_{2} \mathrm{O}$ were also observed in this ash. A similar composition was observed by Frías et al. ${ }^{13}$ which indicated $\mathrm{SiO}_{2}$ as a major oxide $(70 \%)$ and $\mathrm{CaO}, \mathrm{SO}_{3}$, and $\mathrm{K}_{2} \mathrm{O}$ (in this same sequence) as minor compounds. The loss on ignition of $3.5 \%$ was expressively lower than the $6.0 \%$ established in the Brazilian standard NBR $12653^{29}$ or the $10.0 \%$ defined by the ASTM C618-15..$^{30}$ In particular, this result confirmed the effectiveness of the two-step calcination process used to remove organic compounds, and the importance of the prior characterization of the SCS by TGA.

Table 4. Oxide percentages (by mass) and loss on ignition of SCSA samples

\begin{tabular}{lccc}
\hline Oxide & IN-SCSA & WW-SCSA & HL-SCSA \\
\hline $\mathrm{SiO}_{2}$ & 73.4 & 83.0 & 94.8 \\
$\mathrm{Al}_{2} \mathrm{O}_{3}$ & 0.7 & 2.6 & 1.4 \\
$\mathrm{Fe}_{2} \mathrm{O}_{3}$ & 0.4 & 0.5 & 0.2 \\
$\mathrm{~K}_{2} \mathrm{O}$ & 5.5 & 2.1 & 0.2 \\
$\mathrm{SO}_{3}$ & 7.2 & 2.7 & 1.9 \\
$\mathrm{P}_{2} \mathrm{O}_{5}$ & 0.6 & - & - \\
$\mathrm{Ti}_{2} \mathrm{O}$ & 0.1 & 0.1 & 0.1 \\
$\mathrm{MnO}$ & 0.2 & 0.1 & - \\
$\mathrm{CaO}$ & 8.4 & 6.7 & 0.1 \\
Loss on ignition & 3.5 & 2.2 & 1.2 \\
\hline
\end{tabular}

Silica content was approximately $13 \%$ higher in WW-SCSA, in comparison with IN-SCSA. This was due to the removal of $\mathrm{K}_{2} \mathrm{O}$ and $\mathrm{SO}_{3}$ during the hot water treatment, as also indicated in Table 4. On the other hand, the loss on ignition value of WW-SCSA was significantly lower than that for non-treated ash, thus indicating that the straw was more efficiently burnt after hot water washing. The higher silica content of $94.8 \%$ in HL-SCSA, in comparison with the other ashes, indicated that silica purification was even more effective when acid leaching was used. It is clear that there was a dissolution process of $\mathrm{K}_{2} \mathrm{O}, \mathrm{CaO}$, and $\mathrm{SO}_{3}$, considering previous results obtained for RHA..$^{21,31}$ It is important to note that the loss on ignition of HL-SCSA was only $1.2 \%$.

The visual aspect of SCSAs obtained from different processes confirmed the chemical composition results. The light gray color of IN-SCSA was an indicative of the presence of carbonaceous residues from the incomplete burning of lignocellulose in SCS, which it could be confirmed by the loss on ignition value presented in Table 3. Both WW-SCSA and HL-SCSA were characterized as bright white silica samples, indicating the almost complete burning of organic compounds.

$\mathrm{X}$-ray diffraction patterns are shown in Figure 5. Overall, the diffractograms revealed that the controlled burning at $700{ }^{\circ} \mathrm{C}$ made the crystallization of silica during the removal of organic compounds impossible. The results clearly showed that all ashes were predominantly amorphous, as revealed by the typical diffuse scattering band (amorphous hump) associated with silica $(\mathrm{Cu}-\mathrm{K \alpha}$ $2 \theta$ ranging from 15 to $\left.30^{\circ}\right)$. Crystalline silica as quartz $(\mathrm{Cu}-K \alpha$ $2 \theta$ of $26.65^{\circ}$ ) was present in IN-SCSA, and it was associated with the contamination of straw with sand. This contamination has been commonly detected in SCBA samples. ${ }^{8,14,17,18}$ When SCS samples were pretreated prior to burning, the presence of quartz was not detected. Interestingly, WW-SCSA exhibited a pattern similar to that of HL-SCSA, although the hot washing was a considerably simpler procedure as compared to acid leaching. Furthermore, it is 
very important to observe that silica should remain in the amorphous state, considering both the pozzolanic activity and the minimum risks to humans of inhaling crystalline silica during use. According to the International Agency for Research on Cancer (IARC/WHO), the various forms of crystalline silica, such as quartz, tridymite, and cristobalite presented carcinogenic risks to humans. ${ }^{32}$

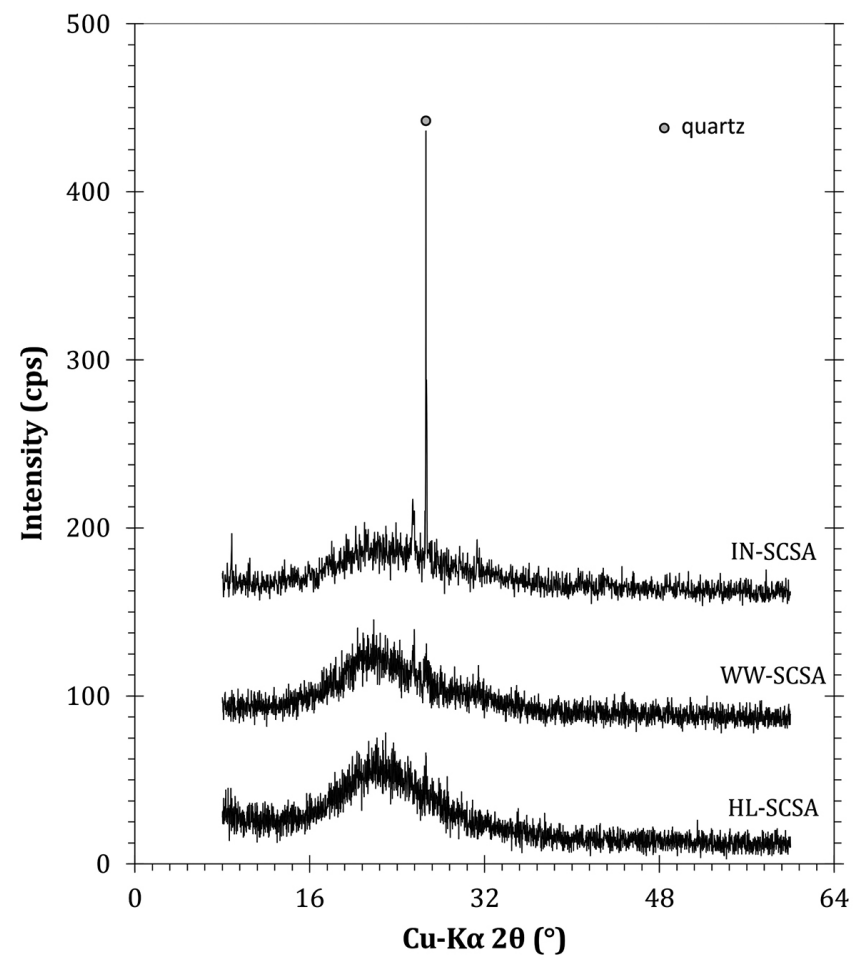

Figure 5. X-ray diffraction patterns of SCSA samples

\section{Pozzolanic activity of ashes}

The typical results of conductivity over time of the SCSAs are shown in Figure 6. IN-SCSA caused a considerable drop in conductivity after only $1 \mathrm{~min}$ in the alkaline solution. However, the decrease in conductivity was more pronounced for the pretreated SCSAs, especially HL-SCSA. As shown in Table 5, the median variation of conductivity after 2 min of IN-SCSA was $1.07 \mathrm{mS} \mathrm{cm}^{-1}$, which allowed classifying this ash as low reactive, in accordance to the Luxan's criterion..$^{26}$ On the other hand, both WW-SCSA and HL-SCSA were classified as

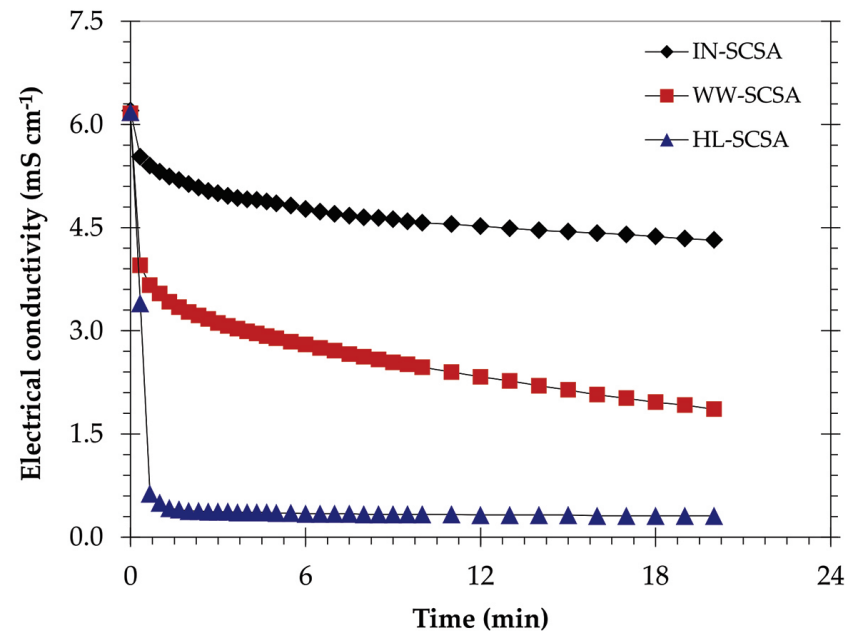

Figure 6. Electrical conductivity values versus time for SCSA samples good pozzolanic materials, with variations of 2.89 and $5.80 \mathrm{mS} \mathrm{cm}^{-1}$, respectively. In this case, the 2 min-decrease was more significantly intense in HL-SCSA. Similar conductivity results were reported by Feng et al. ${ }^{20}$ in a study using HCl-pretreated RHA.

Table 5. Results of pozzolanic activity of SCSA samples. Values of standard deviation are indicated between brackets

\begin{tabular}{lccc}
\hline Characteristic & IN-SCSA & WW-SCSA & HL-SCSA \\
\hline $\begin{array}{l}\text { Variation of con- } \\
\text { ductivity }\left(\mathrm{mS} \mathrm{cm}^{-1}\right)\end{array}$ & $1.07( \pm 0.2)$ & $2.89( \pm 0.2)$ & $5.80( \pm 0.3)$ \\
$\begin{array}{l}\text { Chapelle pozzola- } \\
\text { nic activity }\left(\mathrm{mg} \mathrm{g}^{-1}\right)\end{array}$ & 1071 & 1172 & 1330 \\
\hline
\end{tabular}

Table 5 also shows the results of the modified Chapelle test. The quantity of $\mathrm{Ca}(\mathrm{OH})_{2}$ fixed by SCSA was indicated in this analysis; the higher the $\mathrm{Ca}(\mathrm{OH})_{2}$ (or the original $\mathrm{CaO}$ ) combined with the sample, the higher its pozzolanic activity was. Theoretically, the quantity of $\mathrm{Ca}(\mathrm{OH})_{2}$ fixed by different SCSA samples could be estimated considering Equation 5. However, the calcium silicate hydrate (denominated as C-S-H) formed is a particular variety of C-S-H with variable $\mathrm{CaO} / \mathrm{SiO}_{2}$ molar ratio. Therefore, it is not possible to conclude whether the pozzolanic $\mathrm{C}-\mathrm{S}-\mathrm{H}$ was formed from a fully reacted $\mathrm{SiO}_{2}$. Some studies have found $\mathrm{CaO} / \mathrm{SiO}_{2}$ ratios varying from 0.7 to 1.0 for $\mathrm{C}-\mathrm{S}-\mathrm{H}$ formed in pozzolanic reactions of agricultural ashes (i.e., sugar cane bagasse and rice husk ashes). ${ }^{33}$ Thus, it can be seen that all ashes exhibited high pozzolanicity, with values of activity above $1000 \mathrm{mg}$ of $\mathrm{Ca}(\mathrm{OH})_{2}$ per gram of SCSA. This behavior can be attributed to the higher amorphous silica content and, consequently, low loss on ignition of the different ashes. These results were similar to those obtained for silica fume (highly reactive pozzolan). ${ }^{34}$ The Chapelle results had the same trend as that observed in conductivity tests. Both WW-SCSA and HL-SCSA presented pozzolanic activity expressively higher than the non-pretreated sample, indicating that the removal of straw impurities, in fact, increases the pozzolanic activity of this type of ash.

$$
x \mathrm{SiO}_{2}+y \mathrm{CaO}+z \mathrm{H}_{2} \mathrm{O} \rightarrow y \mathrm{CaO} \bullet x \mathrm{SiO}_{2} \bullet z \mathrm{H}_{2} \mathrm{O}
$$

A comparison between both pozzolanic activity tests concerning the silica content of SCSAs is shown in Figure 7. There was a direct linear relationship between the Lúxan's 2 min- $\Delta C$ parameter and the silica content. As expected, the results indicated a strong dependence of pozzolanic activity on the presence of amorphous silica. The same trend was observed for the pozzolanic activity measured using the Chapelle method since both relationships shown in Figure 7 exhibited coefficients of determination $\left(\mathrm{R}^{2}\right)$ higher than 0.99 . These results also confirmed the good correlation between the measurements of electrical conductivity and the Chappelle method to analyze SCSA. It was probable that the low carbon content and the pronounced silica content at the amorphous state contributed for those good correlations.

Contrasting with the previous discussion, an analysis of the relationship between the pozzolanic activities and the BET specific surface areas did not lead to similar correlations. In this case, the pozzolanic activity values were higher for the pretreated ashes, but the expressive increase observed in the specific surface for HL-SCSA did not follow the same increase in pozzolanic activity in relation to the other ashes. It seems that the pozzolanic activity of bio-silica materials, such as SCSA, was mainly associated with the outer specific surface area, i.e. the specific surface related to the external pores. ${ }^{28}$ This could be attributed to the $\mathrm{N}_{2}$-adsorption specific surface of SCSA, which was strongly influenced by the internal porous structure of the particles (Figure 4). 


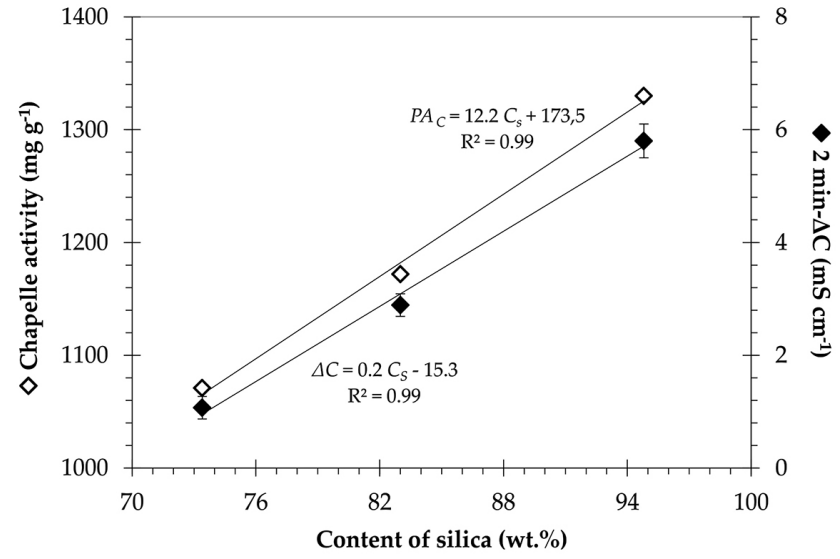

Figure 7. Correlation between both 2 min- $\Delta C$ (full symbols) and Chapelle pozzolanic activity $\left(P A_{C}\right.$ indicated by hollow symbols) and the silica content $\left(C_{S}\right)$ for SCSA samples

Finally, it is worth noting that both pretreatments described in this work could be performed in sugar-ethanol mills, especially the hot water washing. This because steam and hot water are abundantly produced from burning of bagasse or sugar cane straw.

\section{CONCLUSIONS}

The pozzolanic behavior of SCSA produced from different sugar cane straws (non-pretreated and pretreated samples) was investigated in this work. The results showed that both hot water washing and acid leaching pretreatments of SCS were effective to produce SCSAs with high purity silica, associated with the removal of impurities, especially $\mathrm{CaO}, \mathrm{SO}_{3}$, and $\mathrm{K}_{2} \mathrm{O}$. The effect of the hot water washing treatment was relatively small in relation to the acid leaching, but the hot washed SCSA was significantly higher than that of non-pretreated ash. The characteristics of SCSAs indicated that the burning and dry-grinding procedures appeared to be appropriate for producing SCSA with pozzolanic properties. Amorphous structured silica was observed in the three SCSAs available in this study, irrespective of whether pretreatments were performed or not. Direct linear relationships were observed between the Lúxan and Chapelle activities and the silica content of SCSA. However, this behavior was not observed when pozzolanic activity data were contrasted with the BET specific surface area values of distinct SCSA samples.

Further research should also consider other sugar cane straw samples and leaching pretreatments. Moreover, additional experiments are needed to be performed in concrete application to confirm the obtained results.

\section{ACKNOWLEDGEMENTS}

This research has been supported by the National Counsel of Technological and Scientific Development (CNPq) of Brazil (Project number 309516/2015-3). We also thank the UFRRJ (campus Dr. Leonel Miranda) for the provision of sugar cane straw sample.

\section{REFERENCES}

1. http://www.fao.org, accessed in January 2017.

2. http://www.ibge.gov.br, accessed in January 2017.

3. Aguiar, D. A.; Silva, W. F.; Rudorff, B. F. T.; Adami M.; Proceedings of the ISPRS TC VII Symposium - 100 Years ISPRS, Vienna, Austria, 2010.
4. Rípoli, T. C. C.; Molina Jr., W. F.; Rípoli, M. L. C.; Sci. Agric. 2000, 57, 677.

5. Wiedenfeld, B.; J. Am. Soc. Sugar Cane Technol. 2009, 29, 102.

6. Bauen, A.; Cortez, L.; Rosillo-Calle, F.; Bajay, S.; Proceedings of the $10^{\text {th }}$ European Conference and Technology Exhibition on Biomass for Energy and Industry, Würzburg, Germany, 1988.

7. Payá, J.; Monzó, J.; Borrachero, M. V.; Díaz-Pinzón, L.; Ordónez, L. M.; J. Chem. Technol. Biotechnol. 2002, 77, 321.

8. Ganesan, K.; Rajagopal, K.; Thangavel, K.; Cem. Concr. Compos. 2007, 29,515 .

9. Cordeiro, G. C.; Toledo Filho, R. D.; Tavares, L. M.; Fairbairn, E. M. R.; Cem. Concr. Compos. 2008, 30, 410.

10. Fairbairn, E. M. R.; Americano, B. B.; Cordeiro, G. C.; Paula, T. P.; Toledo Filho, R. D.; Silvoso, M. M.; J. Environ. Manage. 2010, 91, 1864.

11. Cordeiro, G. C.; Toledo Filho, R. D.; Fairbairn, E. M. R.; Constr. Build. Mater. 2009, 23, 3301.

12. Martirena, F.; Middendorf, B.; Day, R. L.; Gehrke, M.; Roque, P.; Martínez, L.; Betancourt, S.; Cem. Concr. Res. 2006, 36, 1056.

13. Frías, M.; Villar-Cociña, E.; Valencia-Morales, E.; Waste Manege. 2007, 27,533

14. Morales, E. V.; Villar-cociña, E.; Frías, M.; Santos, S. F.; Savastano Jr., H.; Cem. Concr. Compos. 2009, 31, 22.

15. Moraes, J. C. B.; Akasaki, J. L.; Melges, J. L. P.; Monzó, J.; Borrachero, M. V.; Soriano, L.; Payá, J.; Tashima, M. M.; Constr. Build. Mater. 2016, 94, 670 .

16. Cordeiro, G. C.; Toledo Filho, R. D.; Fairbairn, E. M. R.; Quim. Nova 2009, 32, 82 .

17. Cordeiro, G. C.; Toledo Filho, R. D.; Tavares, L. M.; Fairbairn, E. M. R.; Cem. Concr. Res. 2009, 39, 110.

18. Cordeiro, G. C.; Toledo Filho, R. D.; Tavares, L. M.; Cem. Concr. Res. 2016, 89, 269.

19. Krishnarao, R. V.; Subrahmanyam, J.; Kumar, T. J.; J. Eur. Ceram. Soc. 2001, 21, 99.

20. Feng, Q.; Yamamichi, H.; Shoya, M.; Sugita, S.; Cem. Concr. Res. 2004, $34,521$.

21. Chakraverty, A.; Mishra, P.; Banerjee, H. D.; J. Mater. Sci. 1988, 23, 21.

22. Real, C.; Alcala, M. D.; Criado, J. M.; J. Am. Cer. Soc. 1996, 79, 2012.

23. Cordeiro, G. C.; Sales, C. P.; Cem. Concr. Compos. 2016, 73, 98.

24. Cordeiro, G. C.; Sales, C. P.; Cem. Concr. Compos. 2015, 55, 331.

25. American Society for Testing and Materials; Standard test methods for chemical analysis of hydraulic cement, ASTM C114-15, West Conshohocken, USA, 2015.

26. Luxán, M. P.; Madruga, F.; Saavedra, J.; Cem. Concr. Res. 1989, 19, 63.

27. Raverdy, M.; Brivot, F.; Paillère, A. M.; Bron, R.; Proceedings of the $7 e$ Congrès International de la Chimie des Ciments, Paris, France, 1980.

28. Cordeiro, G. C.; Toledo Filho, R. D.; Tavares, L. M.; Fairbairn, E. M. R.; Hempel, S.; Cem. Concr. Compos. 2011, 33, 529.

29. Associação Brasileira de Normas Técnicas; Materiais pozolânicos, NBR 12653, Rio de Janeiro, Brasil, 2014.

30. American Society for Testing and Materials; Standard Specification for coal fly ash and raw or calcined natural pozzolan for use in concrete, ASTM C618-15, West Conshohocken, USA, 2015.

31. Umeda, J.; Kondoh, K. Trans. JWRI 2008, 37, 13.

32. Greenberg, M. I.; Waksman, J.; Curtis, J.; Dis. Mon. 2007, 53, 394.

33. Souza, L. M. S.; Fairbairn, E. M. R.; Toledo Filho, R. D.; Cordeiro, G. C.; Quim. Nova 2014, 37, 1600 .

34. Quarcioni, V. A.; Chotoli, F. F.; Coelho, A. C. V.; Cincotto, M. A.; IBRACON Structures and Materials Journal 2015, 8, 1. 